\title{
The Performance Research and Orthogonal Analysis of Humidification-dehumidification Technology (HDH) System
}

\author{
Hongyu Ge, Yisong Cai, Sitong Li, Kaimin Wang and Xiaohua Liu*
}

Key Laboratory of Ocean Energy Utilization and Energy Conservation of Ministry of Education, School of Energy and Power Engineering, Dalian University of Technology, Dalian 116024, China.

\begin{abstract}
HDH seawater desalination technology has characteristics of flexible scale, small investment, and suitable for decentralized fresh water demand. This paper designs a HDH seawater desalination system, and based on the principles of energy conservation and mass conservation, a theoretical calculation model is established, and the influence of spray liquid flow and temperature, airflow, cooling water temperature and flow on the system water production and Gained output ration (GOR) is studied. And the orthogonal analysis method is used to study the influence of different parameters on water production and GOR. The results show that: water production and GOR are positively related to temperature of the spray liquid, when spray liquid or air flow is large, fresh water output is negatively correlated with air flow, system water production and cooling water flow are positively correlated at first, then system fresh water production tends to be stable, GOR and cooling water flow are first negatively correlated, and then GOR become stable, water production is negatively correlated with cooling water temperature, GOR is positively correlated with cooling water temperature. The spray liquid flow rate has the greatest influence on water production, and spray liquid temperature has the greatest influence on GOR.
\end{abstract}

\section{Introduction}

The survival and development of human society are inseparable from water. The earth is rich in water resources, with a total water storage of approximately 1.4 billion cubic kilometers. However, sea water, brackish water and other water that cannot be directly used for drinking and irrigation account for more than $97 \%$ of the earth's total water storage, and the remaining less than $3 \%$ of fresh water, but most of them are frozen in the glaciers at the poles and alpine regions of the earth, and the remaining fresh water is distributed more underground than surface water. The fresh water that exists in rivers, lakes and other places on the earth is less than $0.36 \%$ to directly be used by humans [1].

At present, the mainstream seawater desalination technologies include low-temperature multi-effect distillation (LT-MED), multi-stage flash evaporation (MSF) and reverse osmosis (RO), etc. However, these technologies and equipment require large investment,

\footnotetext{
*Corresponding author: 1xh723@dlut.edu.cn
} 
high energy consumption, and high maintenance costs. The requirements of pre-treatment processing are strict, and it is necessary to reduce the cost of fresh water through the large-scale production of fresh water. And most of the seawater desalination devices with mature technology and commercial production are traditional large-scale devices, are suitable for energy-rich economically developed regions [2], which cannot effectively solve the shortage of fresh water in remote and scattered areas. HDH avoids the above-mentioned problems. Its main characteristics are: flexible scale, small investment, suitable for decentralized fresh water demand, the vaporization process takes place at the gas-liquid interface instead of the heat transfer surface, which avoids scaling on the heat transfer surface and reduces the pretreatment requirements for seawater. The initial form of HDH seawater desalination system is a solar distiller. Humidifier and dehumidifier are its two most important components. Air is used as the carrier to bring water vapor from the humidifier to the dehumidifier for condensation. And concentrated brine is also obtained in the vessel, which shows that HDH technology can not only be applied to seawater desalination, but also can be applied to the concentration of waste liquid.

The development of HDH devices has gone through three stages. The first is the natural convection HDH process based on the development of solar distiller. Muller-Hois [3] built a natural convection HDH seawater desalination system. The seawater sprayed from the humidifier transfers heat and mass with the countercurrent air conduct. In this system, the energy utilization rate is not very ideal, because the HDH processes are not separated, and the difference between the evaporation temperature and the condensation temperature is small. In the second stage, the natural convection of the air in the first stage is replaced by forced convection. The flow velocity of the air becomes larger, and improves the efficiency of heat and mass transfer, thereby increasing the production of fresh water. Veza [4] built a $\mathrm{HDH}$ seawater desalination device, which adopts forced air convection, and the efficiency of system have been greatly improved. The third stage is the separation of the humidification process and the dehumidification process. Most scholars use this form of HDH device for experimental research, and build various systems on the basis of this structure [5-10]. AI-Hallaj[11] established a typical representative of a separate HDH device, the latent heat of condensation is recovered in the water, and the fresh water output of the device is 2 to5 times that of the distiller under the same conditions. Albers [12] proposed the dew point evaporation seawater desalination technology. The heat of the condensation chamber is directly transferred to the evaporation chamber, and the energy utilization rate is improved. After that, in the system that adopted the falling film mass transfer method in the vertical falling film dew point evaporator [13], after the sea water fell into the evaporation chamber, it contacted the surface of the evaporator. The results showed that it was different from the conventional device, the water production and energy recovery coefficient can be increased by 1.5 times. .Rajaseenivasan [14] analyzed the bubbling tower HDH seawater desalination system with different combinations of solar collectors. The results showed that the performance of the system improved with the increase of air flow and cooling water flow. Lawal [15] experimentally studied the performance of the HDH system driven by the heat pump. The proposed integrated unit can produce fresh water, and the cooling effect is adjusted by the heat exchange unit by water heating or cooling. Srithar[16] used HDH process to recover the waste heat of the condenser and the evaporator, and improved the performance of the refrigeration system by circulating the humid air around the condenser coil and condensing humid air on the surface of the evaporator coil.

In terms of theoretical analysis, Nafey [17-18] first established mathematical models of different heating methods for HDH systems. For the analysis of a heat pump-driven HDH desalination system shows that the influence of temperature on the system productivity is not obvious [19]. Moumouh [20] studied a mathematical model for the design of a 
humidification-dehumidification desalination device based on air HDH. The mathematical model predicted the heat exchange of the desalination device and calculated the outlet temperature of each device. For the study of multi-effect mathematical models for humidifiers, dehumidifiers and heat exchangers showed that: the water production rate of the system is higher than the one-effect system and the three-effect system [21]. And the influence of different parameters on the performance of a dual heat and mass coupled HDH system is studied. The results showed that when other parameters are constant, as the amount of feed seawater increases, fresh water production and heat input increase, but GOR decreases.

In summary, the HDH seawater desalination technology has greater practical application prospects, and has become a research hotspot in recent years. But there isn't systematic conclusions have been formed, and further research is still needed. This paper proposes a $\mathrm{HDH}$ system based on the plate tower humidifier, and conducts theoretical analysis and calculations to provide guidance for subsequent experimental research and practical engineering applications.

\section{Mathematical model and solution of HDH system}

According to the operating characteristics of the actual system, the model is simplified for the convenience of analysis:

- No heat loss.

- The humid air is saturated at the inlet and outlet of the humidifier.

- The processes involved are all working conditions under the stable operation of the system.

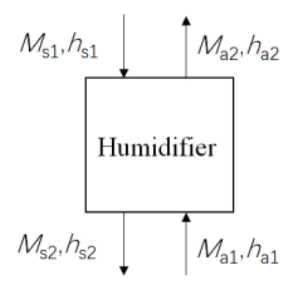

Fig. 1. Humidifier model

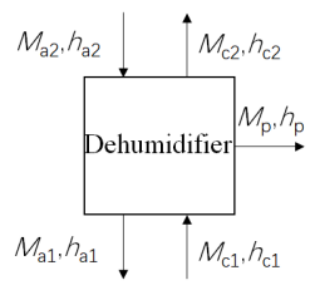

Fig. 2. Dehumidifier model

According to the work process, the energy conservation equation and mass conservation equation in the humidifier are established [23-24].

In the humidifier, according to the conservation of energy, the heat released by the liquid is equal to the heat absorbed by the humid air, the energy conservation equation is as follows:

$$
M_{\mathrm{s} 1} h_{\mathrm{s} 1}-M_{\mathrm{s} 2} h_{\mathrm{s} 2}=M_{\mathrm{a}}\left(h_{\mathrm{a} 2}-h_{\mathrm{a} 1}\right)
$$

Where $M_{s 1}$ is the mass flow of the liquid spray, $\mathrm{kg} / \mathrm{s}, \mathrm{h}_{\mathrm{s} 1}$ is the specific enthalpy of the liquid at the top of the humidifier, $\mathrm{kJ} / \mathrm{kg}, \mathrm{M}_{\mathrm{s} 2}$ is the mass flow of the liquid from the humidifier outlet $\mathrm{kg} / \mathrm{s}, \mathrm{h}_{\mathrm{s} 2}$ It represents the specific enthalpy value of the liquid at the outlet of the humidifier, $\mathrm{kJ} / \mathrm{kg}, \mathrm{M}_{\mathrm{a}}$ is the mass flow of dry air, $\mathrm{kg} / \mathrm{s}, \mathrm{h}_{\mathrm{a} 2}$ represents the specific enthalpy of the humid air at the outlet of the humidifier, $\mathrm{kJ} / \mathrm{kg}, \mathrm{h}_{\mathrm{a} 1}$ represents the specific enthalpy of humidity air at the inlet of the humidifier, $\mathrm{kJ} / \mathrm{kg}$.

The mass of humid air in the humidifier changes with the liquid, so the mass conservation equation must be used in theoretical calculations. The mass conservation equation is as follows: 


$$
M_{\mathrm{s} 1}-M_{\mathrm{s} 2}=M_{\mathrm{a}}\left(d_{\mathrm{a} 2}-d_{\mathrm{a} 1}\right)
$$

Where $d_{a 1}$ and $d_{a 2}$ are the moisture content of the humidifier inlet and outlet, $\mathrm{kg} / \mathrm{kg}$.

In the dehumidifier, according to the conservation of energy, the heat released by the humid air is equal to the heat absorbed by the cooling water. The energy conservation equation is as follows:

$$
M_{\mathrm{c}} h_{\mathrm{c} 2}-M_{\mathrm{c}} h_{\mathrm{c} 1}=M_{\mathrm{a}}\left(h_{\mathrm{a} 2}-h_{\mathrm{a} 1}\right)+M_{\mathrm{p}} h_{\mathrm{p}}
$$

Where $M_{p}$ is the water production rate, $\mathrm{kg} / \mathrm{s} ; \mathrm{h}_{\mathrm{p}}$ is the latent heat of condensation of fresh water, $\mathrm{kJ} / \mathrm{kg}$.

Water vapor is condensed into fresh water in the dehumidifier, so the mass conservation equation is as follows:

$$
M_{\mathrm{p}}=M_{\mathrm{a}}\left(d_{\mathrm{a} 2}-d_{\mathrm{a} 1}\right)
$$

Reference HDH related literature [25-26], the main research performance parameters are as follows:

- System water production

The water production of the system characterizes the ability of the system to produce fresh water. The unit generally adopts $\mathrm{kg} / \mathrm{s}, \mathrm{kg} / \mathrm{h}$ or $\mathrm{kg} / \mathrm{d}$. This article adopts the unit of $\mathrm{kg} / \mathrm{s}$.

- GOR

The definition of GOR is as follows:

$$
\mathrm{GOR}=\frac{M_{p} h_{p}}{Q_{w}}
$$

In this paper, a mathematical model of the HDH system is established, and the iterative method is used to calculate unknown parameters by MATLAB program. The calculation flow chart is shown in Figure 3. The flow $\mathrm{M}_{\mathrm{s} 1}$ and temperature $t_{\mathrm{s} 1}$ of the liquid at inlet of the humidifier are known. And the temperature $\mathrm{ta}_{1}{ }^{\prime}$ of the humid air at inlet of the humidifier is assumed, so that the state of the humidified air at inlet of the humidifier is also known. The actual heat exchange can be obtained from efficiency formula, and then the temperature of the humid air at the outlet of the humidifier and various parameters can be obtained. Regarding the obtained state parameters of humidifier outlet as the state parameters of the humid air at inlet of the dehumidifier. Then the humid air temperature ta ${ }_{1}$ " at outlet of the dehumidifier is calculated according to the actual heat exchange, replacing $\operatorname{ta}_{1}{ }^{\prime}$ until the difference between $\mathrm{ta}_{1}{ }^{\prime}$ and $\mathrm{ta}_{1}{ }^{\prime}$ meets the convergence condition, and end the iteration work.

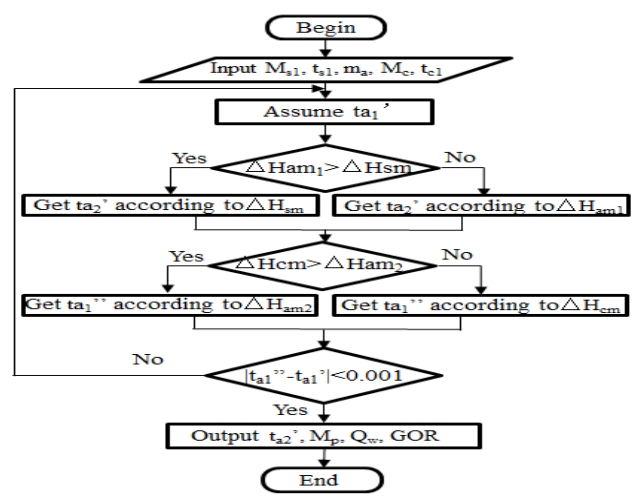

Fig. 3. Calculation flow chart of humidification and dehumidification system 


\section{Results and discussion}

\subsection{The influence of spray liquid and air}

The temperature of the spray liquid is a key factor of affecting the performance of the entire $\mathrm{HDH}$ system. At this time, the air flow $\mathrm{M}_{\mathrm{a}}$ is $0.018 \mathrm{~kg} / \mathrm{s}$, the cooling water flow $\mathrm{M}_{\mathrm{c}}$ is 0.03 $\mathrm{kg} / \mathrm{s}$, and the dehumidifier inlet cooling water temperature $t_{\mathrm{c} 1}$ is $20^{\circ} \mathrm{C}$. Figure 4 shows that the water production is positively correlated with the temperature of spray liquid. This is because the humidification capacity of the humidifier has been improved, so the fresh water production promotes. When the flow of the spray liquid is constant, as the temperature of the spray liquid increases, the GOR increases (Figure 5). This is because the temperature of the spray liquid increases, the heat released by the humid air in the dehumidifier increases more than the increase of the input heat, and the GOR increases. GOR increases with the increase of the spray liquid flow.

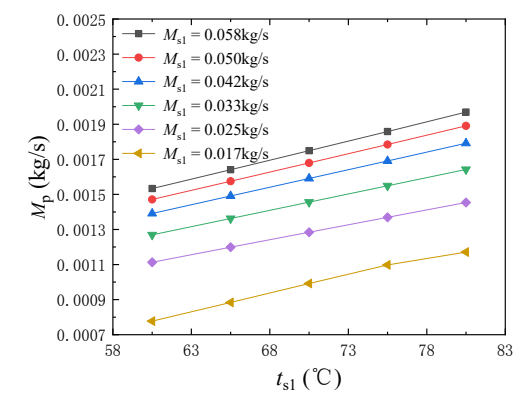

Fig. 4. The system water production varies

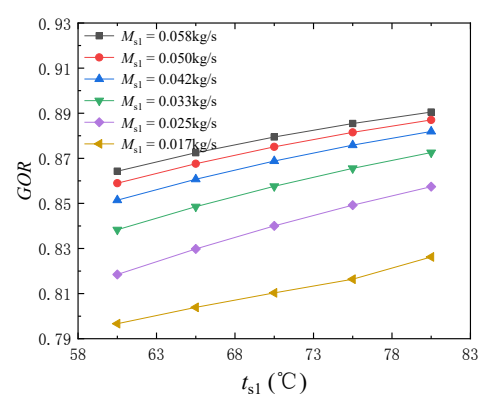

Fig. 5. The GOR varies with spray liquid temperature

With seawater spray temperature

Besides, as a carrier of water vapor, the flow of air also has an important impact on the performance of the system. At this time, the spray liquid temperature $t_{s 1}$ is $70^{\circ} \mathrm{C}, \mathrm{M}_{\mathrm{c}}$ is 0.03 $\mathrm{kg} / \mathrm{s}$, and $\mathrm{t}_{\mathrm{c} 1}$ is $20^{\circ} \mathrm{C}$.

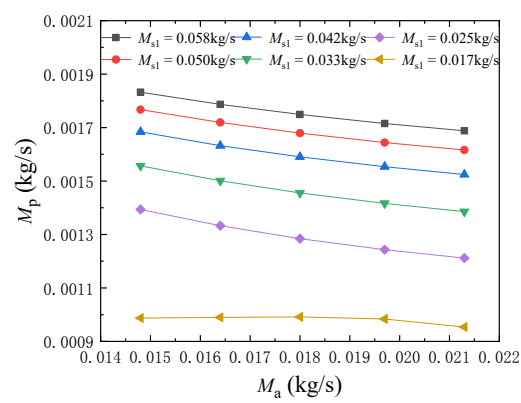

Fig. 6. The system water production

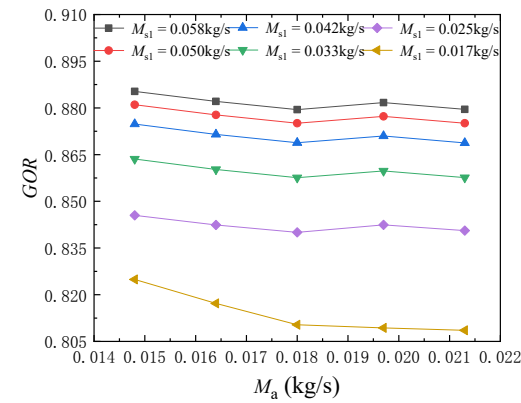

Fig. 7. The GOR varies with air flow

Varies with air flow

Figure 6 shows the variation curve of the system water production with air flow. The water production of the system is determined by the difference of moisture content of the humid air at inlet and outlet of dehumidifier and air flow. Under high spray liquid flow, the 
difference of moisture content changes more than air flow; it has a greater impact on the system water production, resulting in a decrease of the system water production. Under the low spray liquid flow, the difference of moisture content is smaller than the other working conditions, so the system water production is not basically change with influence of air flow increasing. Figure 7 shows the change of GOR with the air flow rate. It can be seen that under low fluid flow conditions, the heat input to system increases while the system water production is basically unchanged, resulting in a decrease of GOR. In the other case of other spray liquid flow, as the air flow rate increases, GOR shows a trend of decreasing at first, then increasing, and then decreasing. This is because the changes of fresh water production and heat input to system are different.

\subsection{The influence of cooling water}

At this time, the spray liquid temperature is $70^{\circ} \mathrm{C}$, the air flow rate is $0.0180 \mathrm{~kg} / \mathrm{s}$, and the cooling water temperature is $20^{\circ} \mathrm{C}$.

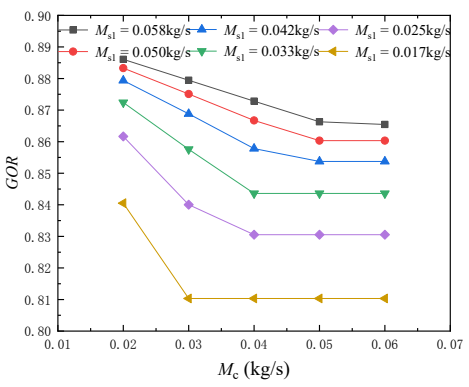

Fig. 8. GOR varies with cooling water flow

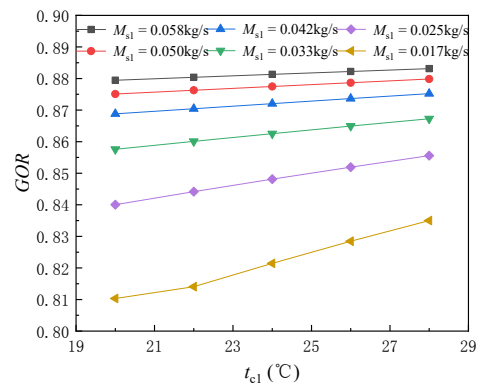

Fig. 9. GOR varies with cooling water temperature

Figure 8 shows the change of GOR with the cooling water flow. After the critical cooling water flow rate, the system water production and heat input to system no longer change with the cooling water flow rate, so the GOR does not change. Before the critical value, GOR decrease as the cooling water flow increases. This is because the flow of cooling water increases, heat input to system increases more than heat released by humid air in the dehumidifier. From Figure 9, it can be seen that the dehumidification capacity of the dehumidifier is relatively large when spray liquid flow is small. The water production is constant; more heat must be input to maintain the operation of the system. Therefore, when the cooling water temperature increases, the dehumidification capacity reduced, so that GOR increases.

\subsection{Orthogonal analysis}

The above content analyzes the key parameters that affect the performance of the HDH system, and obtains the change law of the influence of a single parameter on the system performance, but different parameters have mutual influence. This paper uses orthogonal analysis to determine the best engineering condition.

Orthogonal experiment is a design method for studying multiple factors. According to the orthogonally, the most representative operating point is selected from all operating conditions for analysis, and the optimal one is found through the analysis of these operating conditions [27]. 
Table 1. Orthogonal analysis table of water production

\begin{tabular}{cccccc}
\hline Factor & $\begin{array}{c}\text { Spray liquid flow } \\
(\mathrm{kg} / \mathrm{s})\end{array}$ & $\begin{array}{c}\text { Spray liquid } \\
\text { temperature } \\
\left({ }^{\circ} \mathrm{C}\right)\end{array}$ & $\begin{array}{c}\text { Air flow } \\
(\mathrm{kg} / \mathrm{s})\end{array}$ & $\begin{array}{c}\text { Cooling water } \\
\text { flow } \\
(\mathrm{kg} / \mathrm{s})\end{array}$ & $\begin{array}{c}\text { Cooling water } \\
\text { temperature } \\
\left({ }^{\circ} \mathrm{C}\right)\end{array}$ \\
\hline $\mathrm{K} 1$ & 0.004511 & 0.006145 & 0.007876 & 0.004558 & 0.008047 \\
$\mathrm{~K} 3$ & 0.006056 & 0.006247 & 0.007140 & 0.006443 & 0.006443 \\
$\mathrm{~K} 4$ & 0.007435 & 0.007493 & 0.006974 & 0.007920 & 0.007920 \\
$\mathrm{~K} 5$ & 0.008552 & 0.007580 & 0.006803 & 0.008942 & 0.007275 \\
$\mathrm{k} 1$ & 0.009868 & 0.008957 & 0.007629 & 0.008559 & 0.006894 \\
$\mathrm{k} 2$ & 0.000902 & 0.001229 & 0.001575 & 0.000912 & 0.001609 \\
$\mathrm{k} 3$ & 0.001211 & 0.001249 & 0.001430 & 0.001289 & 0.001289 \\
$\mathrm{k} 4$ & 0.001487 & 0.001499 & 0.001395 & 0.001584 & 0.001584 \\
$\mathrm{k} 5$ & 0.001710 & 0.001516 & 0.001361 & 0.001788 & 0.001455 \\
the extreme & 0.001974 & 0.001791 & 0.001526 & 0.001712 & 0.001379 \\
difference & 0.000562 & 0.000562 & 0.000214 & 0.000876 & 0.000320 \\
\hline
\end{tabular}

It can be seen from Table 1 that the effects of various factors on the water production are arranged in descending order: spray liquid flow, cooling water flow rate, spray liquid temperature, cooling water temperature, and air flow.

Table 2. Orthogonal analysis table of GOR

\begin{tabular}{|c|c|c|c|c|c|}
\hline Factor & $\begin{array}{l}\text { Spray liquid } \\
\text { flow }(\mathrm{kg} / \mathrm{s})\end{array}$ & $\begin{array}{c}\text { Spray liquid } \\
\text { temperature }\left({ }^{\circ} \mathrm{C}\right)\end{array}$ & $\begin{array}{c}\text { Air } \\
\text { flow }(\mathrm{kg} / \mathrm{s})\end{array}$ & $\begin{array}{l}\text { Cooling water } \\
\text { flow }(\mathrm{kg} / \mathrm{s})\end{array}$ & $\begin{array}{l}\text { Cooling water } \\
\text { temperature }\left({ }^{\circ} \mathrm{C}\right)\end{array}$ \\
\hline K1 & 4.127 & 4.194 & 4.285 & 4.354 & 4.241 \\
\hline $\mathrm{K} 2$ & 4.123 & 4.242 & 4.269 & 4.292 & 4.292 \\
\hline K3 & 4.137 & 4.267 & 4.288 & 4.234 & 4.234 \\
\hline K4 & 4.133 & 4.314 & 4.246 & 4.233 & 4.291 \\
\hline K5 & 4.158 & 4.325 & 4.254 & 4.229 & 4.288 \\
\hline $\mathrm{k} 1$ & 0.8254 & 0.8388 & 0.8570 & 0.8708 & 0.8482 \\
\hline $\mathrm{k} 2$ & 0.8246 & 0.8484 & 0.8538 & 0.8584 & 0.8584 \\
\hline $\mathrm{k} 3$ & 0.8274 & 0.8534 & 0.8576 & 0.8468 & 0.8468 \\
\hline $\mathrm{k} 4$ & 0.8266 & 0.8628 & 0.8492 & 0.8466 & 0.8582 \\
\hline k5 & 0.8316 & 0.8650 & 0.8508 & 0.8458 & 0.8576 \\
\hline $\begin{array}{l}\text { the extreme } \\
\text { difference }\end{array}$ & 0.0070 & 0.0262 & 0.0084 & 0.0250 & 0.0114 \\
\hline
\end{tabular}

It can be seen from Table 2 that effects of various factors on GOR are arranged in descending order: spray liquid temperature, cooling water flow, cooling water temperature, air flow, and spray liquid flow.

\section{Conclusions}

This paper studies the influence of different parameters such as spray liquid flow rate and temperature, air flow rate, cooling water flow and the humid air temperature at the inlet and outlet of the system on fresh water production and water production ratio. Get the following conclusions:

- As the temperature of the spray liquid increases, the system water production and GOR increase.

- When the spray liquid flow and the air flow are small, the system water production does not change much with the increase of the air flow. When the spray liquid flow rate or air flow rate is large, the fresh water production will increase with the increase of the air flow rate. 
- Before the critical cooling water flow rate, GOR decrease as the cooling water flow increases. Above the critical value, the GOR does not change.

- When the cooling water temperature increase, the dehumidification capacity reduced, so that GOR increases.

- By orthogonal analysis, it is also concluded that the spray liquid flow has the greatest influence on the water production, and the spray liquid temperature has the greatest influence on GOR.

\section{Acknowledgments}

This work is supported by the Special Project of Liaoning Province for the Central Government to Guide Local Technological Development (2021JH6/10500150) and National Natural Science Foundation of China (No. 51476017).

\section{Nomenclature}

\section{Symbols}

\begin{tabular}{cl}
\hline $\mathrm{Ms}_{1}$ & liquid mass flow of humidifier inlet $(\mathrm{kg} / \mathrm{s})$ \\
$\mathrm{Ms}_{2}$ & liquid mass flow of humidifier outlet $(\mathrm{kg} / \mathrm{s})$ \\
$\mathrm{hs}_{1}$ & liquid specific enthalpy of humidifier inlet $(\mathrm{kJ} / \mathrm{kg})$ \\
$\mathrm{hs}_{2}$ & liquid specific enthalpy of humidifier outlet $(\mathrm{kJ} / \mathrm{kg})$ \\
$\mathrm{Ma}$ & mass flow of dry air $(\mathrm{kg} / \mathrm{s})$ \\
$\mathrm{ha}_{1}$ & specific enthalpy of air at inlet humidifier $(\mathrm{kJ} / \mathrm{kg})$ \\
$\mathrm{ha}_{2}$ & specific enthalpy of air at outlet humidifier $(\mathrm{kJ} / \mathrm{kg})$ \\
$\mathrm{Mc}_{1}$ & mass flow of cool water $(\mathrm{kg} / \mathrm{s})$ \\
$\mathrm{hc}_{1}$ & specific enthalpy of inlet cool water $(\mathrm{kJ} / \mathrm{kg})$ \\
$\mathrm{hc}_{2}$ & specific enthalpy of outlet cool water $(\mathrm{kJ} / \mathrm{kg})$ \\
$\mathrm{Mp}$ & water production rate $(\mathrm{kg} / \mathrm{s})$ \\
$\mathrm{hp}$ & latent heat of condensation fresh water $(\mathrm{kJ} / \mathrm{kg})$ \\
$\mathrm{Qw}$ & heat input to system $(\mathrm{kJ})$ \\
$\mathrm{ts}_{1}$ & liquid temperature of humidifier inlet $\left({ }^{\circ} \mathrm{C}\right)$ \\
$\mathrm{tc}_{1}$ & cool water temperature of humidifier inlet $\left({ }^{\circ} \mathrm{C}\right)$ \\
$\mathrm{ta}_{1}$ & temperature of air at inlet humidifier $\left({ }^{\circ} \mathrm{C}\right)$ \\
$\mathrm{ta}_{1}{ }^{\prime}$ & assume temperature of air at inlet humidifier $\left({ }^{\circ} \mathrm{C}\right)$ \\
$\mathrm{ta}_{1}{ }^{\prime}$, & temperature of air at inlet humidifier after iteration $\left({ }^{\circ} \mathrm{C}\right)$ \\
$\triangle \mathrm{Ham}_{1}$ & maximum theoretical heat exchange of air at humidifier $(\mathrm{kJ})$ \\
$\triangle \mathrm{Ham}_{2}$ & maximum theoretical heat exchange of air at dehumidifier $(\mathrm{kJ})$ \\
$\triangle \mathrm{Hsm}$ & maximum theoretical heat exchange of liquid at humidifier $(\mathrm{kJ})$ \\
$\triangle \mathrm{H}_{\mathrm{cm}}$ & maximum theoretical heat exchange of cool water at dehumidifier $(\mathrm{kJ})$ \\
$\mathrm{ta}_{2}{ }^{\prime}$ & temperature of air at outlet humidifier $\left({ }^{\circ} \mathrm{C}\right)$ \\
\hline
\end{tabular}

\section{References}

[1] Hongfei Zheng 2012 Solar Deslination Principle and Technology (Beijing: Chemical Industry Press) p 1-3

[2] Narayan GP, Sharqawy MH, Summers EK, Lienhard JH, Zubair SM and Antar MA 2010 The potential of solar-driven humidification-dehumidification desalination for small-scale decentralized water production Renewable and Sustainable Energy Reviews 14 1187-201 
[3] Muller-Hoist H, Engelhaedt M, Herve M and Scholkopf W 1998 Renewable Energy 14 311-318

[4] Veza J M, Ruiz N 1993 Renewable Energy 3 691-699.

[5] Zamen M, Soufari SM, Vahdat SA, Amidpour M, Zeinali MA, Izanloo H and Aghababaie H 2014 Desalination 332 1-6

[6] Kun Li, Weidong Wu, Kun Hu, Li Wang, Ruoqiu Hua 2019 Desalination 469114099

[7] Yin Zhang, Huan Zhang, Wandong Zheng, Shijun You and Yaran Wang 2019 Desalination 468114076

[8] Lawal D, Antar M, Khalifa A, Zubair S and Al-Sulaiman F 2018 Energy Conversion and Management 161 128-140

[9] H Xu,Y Zhao and YJ Dai 2019 Desalination 452 247-257

[10] Yunsheng Zhao, Hongfei Zheng, Shen Liang, Nan Zhang and Xinglong Ma 2019 Desalination 467 147-157

[11] AI-Hallaj S, Farid MM and Tamimi AR1998 Desalination 120 273-280

[12] Larson R, Albers W, Beckman J and Freeman S 1989 Desalination 73 119-137

[13] Hamieh BM and Beckman JR 2006 Desalination 195 14-25

[14] Rajaseenivasan T, Shanmugam RK, Hareesh VM and Srithar K 2016 Energy 116 459-469

[15] Lawal DU, Antar MA, Khalifa A, Zubair SM and Al-Sulaiman F 2020 Desalination 475114199.

[16] Srithar K, Rajaseenivasan T, Arulmani M, Gnanavel R, Vivar M and Fuentes M 2018 Desalination 439 155-161

[17] Nafey AS, Fath HES, El-Helaby SO and Soliman A 2004 Energy conversion and management 45 1263-77

[18] Nafey AS, Fath HES, El-Helaby SO and Soliman AM 2004 Energy conversion and management 45 1243-1261

[19] Yin Zhang, Huan Zhang, Wandong Zheng, Shijun You and Yaran Wang 2019 Energy Conversion and Managemen 180 641-653

[20] Moumouh J, Tahiri M, Salouhi M and Balli L 2016 International Journal of Hydrogen Energy 41 20818-20822

[21] Mingming Zhu 2015 The Research on The Performance of Solar-driven Humidification-Dehumidification Desalination System (Dalian: Dalian University of Technology) chapter 4 p 59

[22] Xuankai Zhang 2017 Thermal Performance Analysis of a Double Direct Contact Humidification- Dehumidification Desalination System (Nanjing: Nanjing University of Aeronautics and Astronautics) chapter 6 p 77

[23] Narayan GP, Lienhard JH and Zubair SM 2010 International Journal of Thermal Sciences 49 2057-2066

[24] Weidao Shen and Jungeng Tong 2016 Engineering Thermodynamics (Beijing: Higher Education Press) p 40-95

[25] ZH Chang, HF Zheng, YJ Yang, YH Su and ZC Duan 2014 Renewable Energy 69 253-259

[26] YJ Dai and HF Zhang 2000 Desalination 130 169-175

[27] Kaitai Fang and Changxing Ma 2001 Orthogonal and Uniform Experimental Design (Beijing: $\quad$ Science Press) p 35-36 